\title{
Usage of Angiotensin-Converting Enzyme Inhibitor or Angiotensin II Receptor Blocker in Hypertension Intracerebral Hemorrhage
}

This article was published in the following Dove Press journal: Neuropsychiatric Disease and Treatment

\author{
Chao Zhang \\ Jun Zhong \\ Wei-Xiang Chen \\ Xu-Yang Zhang \\ Yu-Hong $\mathrm{Li}$ \\ Teng-Yuan Zhou \\ Yong-Jie Zou \\ Chuan Lan \\ Lan Li \\ Zhao-Pan Lai \\ Hua Feng \\ Rong $\mathrm{Hu}$ (D)
}

Department of Neurosurgery and Key Laboratory of Neurotrauma, Southwest Hospital, Third Military Medical

University (Army Medical University)

Chongqing, 400038, People's Republic of China
Correspondence: Rong Hu; Hua Feng Email huchrong@tmmu.edu.cn; fenghua8888@vip.163.com
Background: Inflammation plays an essential role in secondary brain injury after intracerebral hemorrhage (ICH). Angiotensin-converting enzyme inhibitors (ACEIs) and angiotensin II receptor blockers (ARBs) have been suggested to suppress neuroinflammation after central nervous system (CNS) damage in animal models. However, the role of ACEIs and ARBs in ICH patients with hypertension remains unresolved in clinic. The aim of the present study is to evaluate the effect of ACEIs/ARBs on ICH patients with hypertension using a retrospective, single-center data analysis.

Methods: ICH patients diagnosed by computerized tomographic (CT) at Southwest Hospital, Third Military Medical University were included in the present research from January 2015 to December 2019. According to the medical history for the usage of antihypertensive drugs, patients were assigned into either ACEIs/ARBs group or nonACEIs/ARBs group. Demographics, clinical baseline, radiological documents and treatments were collected and these data were statistically analyzed between the two groups.

Results: A total of $635 \mathrm{ICH}$ patients with hypertension were included and allocated into 2 groups according to the usage of antihypertensive drugs: 281 in the ACEIs/ARBs group and 354 in the non-ACEIs/ARBs group. The results presented that the 3-months mortality and prevalence of ICH-associated pneumonia were lower in ACEIs/ARBs group than that in nonACEIs/ARBs group (5.0\% vs $11.9 \%, \mathrm{p}=0.002 ; 58.4 \%$ vs $66.7 \%, \mathrm{p}=0.031)$. While, there was no significant difference in favorable outcome $(40.2 \%$ vs $33.9 \%, \mathrm{p}=0.101)$ between the two groups. Furthermore, patients in ACEIs/ARBs group exhibited significantly less perihematomal edema volume on days $3(23.5 \pm 14.4$ versus $28.7 \pm 20.1 \mathrm{~mL}, \mathrm{p}=0.045)$ and $7(21.0 \pm$ 13.7 versus $25.7 \pm 17.6 \mathrm{~mL}, \mathrm{p}=0.044$ ), compared to that in non- ACEIs/ARBs group.

Conclusion: The usage of ACEIs/ARBs helps decrease mortality, perihematomal edema volume, and prevalence of ICH-associated pneumonia in ICH patients with hypertension.

Keywords: angiotensin-converting enzyme inhibitor, angiotensin II receptor blocker, inflammation, intracerebral hemorrhage, ICH-associated pneumonia

\section{Introduction}

Hypertension intracerebral hemorrhage (ICH) is associated with high mortality and disability. ${ }^{1-4}$ Few effective treatments are available in the several prospective, randomized, controlled, multicenter trials, except for rapid blood-pressure lowering. ${ }^{5-8}$ Primary brain injury is mainly caused by mechanical damage to the surrounding tissues inducing by dissection and compression of the hematoma formation within the first few hours after ICH onset. ${ }^{9}$ Secondary brain injury caused 
by the physiologic response to the primary brain injury could lead more serious and fatal injury, which plays a key role in the overall prognosis of $\mathrm{ICH}^{9}$ The preclinical studies have suggested that inhibition of neuroinflammation holds beneficial effect on ICH animals after central nervous system (CNS) injury. ${ }^{2,9-13}$

The renin-angiotensin-aldosterone system (RAAS), existing in the cardiovascular system, kidneys and CNS, can influence the outcome of ischemic stroke. ${ }^{14-16}$ Angiotensin (Ang) II is a product of the proteolytic cleavage of Ang I by Angiotensin-converting enzyme (ACE) and is the pivotal protein of the RAAS for the regulation of blood pressure. ${ }^{14}$ Ang II can also produce an inflammatory response by binding to type-1 Ang II receptors. ${ }^{17}$ Angiotensin-converting enzyme inhibitors (ACEIs) and angiotensin II receptor blockers (ARBs) are two critical suppressors of the RAAS and widely used as the first-line anti-hypertensive drugs. ${ }^{18}$ Previous researches have shown that ACEIs/ARBs have multiple neuroprotective effects, such as slowing inflammatory processes, inhibition of fibrinoid necrosis, anti-apoptotic and anti-oxidant effects by the reduction of Ang II in the animal models after CNS injury. ${ }^{2,17,19-24}$ However, the role of ACEIs and ARBs in ICH patients with hypertension remains elusive in clinic. ${ }^{25}$ Herein, the aim of the present study is to evaluate the effect of ACEIs/ARBs on ICH patients with hypertension using a retrospective, single-center data analysis.

\section{Methods}

\section{Study Design and Patient Selection}

This retrospective study was approved by the Ethics Committee of the Southwest Hospital, Third Military Medical University (approval no. KY2020114) and the informed consent for patients was waived.

ICH patients diagnosed by initial computerized tomographic (CT) at Southwest Hospital, Third Military Medical University were included in the present research from January 2015 to December 2019. Patients with a history of hypertension and taking at least one of antihypertensive ACEIs/ARBs drugs was assigned into ACEIs/ARBs group, and without any anti-hypertensive ACEIs/ARBs drugs into non- ACEIs/ARBs group.

Eligibility patients were aged 18 years or older with a spontaneous, non-traumatic ICH with a history of hypertension and taking at least one of anti-hypertensive drugs. Exclusion criteria was as follows: (1) ICH from secondary causes, such as head trauma, aneurysm, vascular malformation, tumor or hemorrhagic transformation of ischemic infarcts; (2) the time from symptom onset to admission more than 3 days; (3) unavailable information of antihypertensive medication. Modified Rankin Scale (mRS) score was measured at 90 days, and an mRS score of 4-6 was defined as unfavorable outcome. ${ }^{7}$

\section{Demographics and $\mathrm{ICH}$ Characteristics}

The usage of antihypertensive drugs before admission and during hospital stay were collected. Demographic data included sex, age, smoking (currently smoking one or more cigarettes per day on a regular basis), ${ }^{26}$ alcohol use ( $\geq 1$ drink per week for 1 year), ${ }^{26}$ previous medical history (diabetes mellitus, coronary artery disease, history of stroke [ischemic stroke and intracerebral hemorrhage], anticoagulant therapy, anti-platelet therapy, and sulfonylureas therapy). Home blood pressure (self-measurement at home or nearby clinic) and blood pressure on admission and Glasgow Coma Score Scale (GCS) on admission also were obtained. Laboratory parameters, including neutrophil count, lymphocyte count, C-reactive protein (CRP), procalcitonin, interleukin-6, blood glucose, were measured. ICH volumes and edema volumes (baseline, 3 days and 7 days) were calculated using a semi-automated threshold-based approach by an experienced investigator who was blinded to clinical and biochemical data. ${ }^{7,27}$ Hematoma location and expansion (more than $6 \mathrm{~mL}$ or $33 \%$ growth compared to the initial ICH volume) were centrally evaluated. ${ }^{28}$ Treatment-related data (surgery and statins therapy) and complications (hydrocephalus, pneumonia, mechanical ventilation, gastrointestinal bleeding and seizures) were also collected.

\section{Statistical Analysis}

Data analyses was performed using SPSS software for Windows (version 18.0, Inc., Chicago, IL). Continuous data were presented as mean \pm Standard Deviation (SD) or median (interquartile ranges [IQRs]) and analyzed by independent group using Student's $t$-test or MannWhitney $U$-test, respectively. Categorical data were presented as counts (percentages) and analyzed by chi-square test or continuity correction test. Significant variables $(\mathrm{p}<$ 0.2 ) were entered into the multivariable analysis via the binary logistic regression model to see whether the use of ACEIs/ARBs was associated with beneficial outcome. General linear models (repeated measures) were performed to analyze the within-subjects' effects of perihematomal edema volume at different time points between 
ACEIs/ARBs group and non-ACEIs/ARBs group. A P $<0.05$ was considered statistically significant.

\section{Results}

A total of $1049 \mathrm{ICH}$ patients were included for initial screening, and 635 patients met the inclusion/exclusion criteria who were analyzed in this study (Figure 1). The remaining patients were allocated into 2 groups based on the usage of ACEIs/ARBs: 281 in the ACEIs/ARBs group and 354 in the non-ACEIs/ARBs group. Baseline characteristics of $\mathrm{ICH}$ patients with hypertension were shown in Table 1 . The mean age was $56 \pm 12$ years with males $(71.7 \%)$. The time of usage of ACEIs/ARBs was $3(0.1-8)$ years. The data of anti-hypertension drugs for the $\mathrm{ICH}$ patients are shown in Table 2. There was no difference between the 2 groups in age, sex, previous diseases, lifestyle factors, and radiological data. Blood pressure was higher in the ACEIs/ARBs group than that in the non-ACEIs/ARBs group (Table 1).

At 3 months, 56 (8.8\%) patients died, 402 (63.3\%) patients had unfavorable outcome and 233 (36.7\%) patients had favorable outcome (Table 3). The mortality and ICHassociated pneumonia in ACEIs/ARBs group were obviously lower than that in non-ACEIs/ARBs group (5.0\% vs $11.9 \%$, $\mathrm{p}=0.002 ; 58.4 \%$ vs $66.7 \%, \mathrm{p}=0.031)$. Non-ACEIs/ARBs (OR $1.282,95 \%$ CI 0.883 to $1.863, \mathrm{p}=0.192$ ) was found to be a significant predictor for mortality after $\mathrm{ICH}$, but not for ICH-associated pneumonia (OR 2.299, 95\% CI 1.124 to $4.700, \mathrm{p}=0.023$ ) in the multivariable analysis. The distribution of $\mathrm{mRS}$ at 3-months was different between patients with or without ACEIs/ARBs treatment $(\mathrm{p}=0.007)$ (Figure 2). Nevertheless, there were no significant difference in favorable outcome $(40.2 \%$ vs $33.9 \%, \mathrm{p}=0.101)$ between patients with or without ACEIs/ARBs treatment.

Perihematomal edema was determined using CT scan, calculated and analyzed in patients with supratentorial $\mathrm{ICH}$, without intraventricular hemorrhage (IVH) and surgical treatments, on days 1, 3 and 7 in the two groups (93 cases in the ACEIs/ARBs group and 93 cases in the non-ACEIs /ARBs group). The results delineated that patients in ACEIs/ ARBs group exhibited significantly less perihematomal edema volume on days $3(23.5 \pm 14.4$ versus $28.7 \pm$ $20.1 \mathrm{~mL}, \mathrm{p}=0.045)$ and $7(21.0 \pm 13.7$ versus $25.7 \pm$ $17.6 \mathrm{~mL}, \mathrm{p}=0.044)$, compared to that in non- ACEIs/ ARBs group (Figure 3). However, the hematoma volume at different time points showed no evident difference between

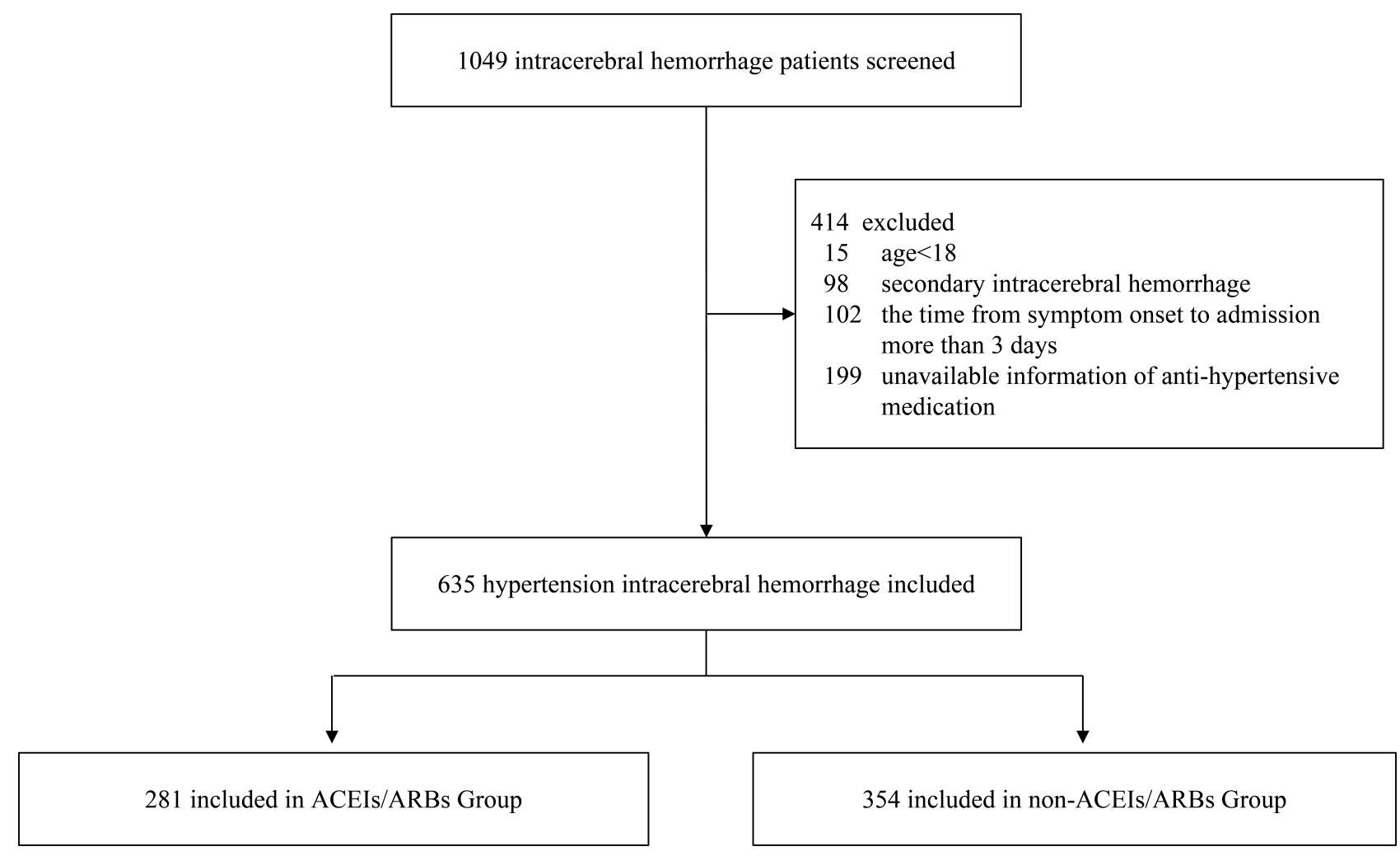

Figure I Flowchart of the selection for study subjects.

Abbreviations: $\mathrm{ICH}$, intracerebral hemorrhage; ACEls, angiotensin-converting enzyme inhibitors; ARBs, angiotensin II receptor blockers. 
Table I Baseline Characteristics of ICH Patients with Hypertension

\begin{tabular}{|c|c|c|c|}
\hline Variables & ACEIs/ARBs $(n=281)$ & Non-ACEIs/ARBs $(n=354)$ & p value \\
\hline Age, $y$, mean $\pm S D$ & $56 \pm 13$ & $57 \pm 12$ & 0.131 \\
\hline Male, n (\%) & $194(69.0)$ & $261(73.7)$ & 0.193 \\
\hline \multicolumn{4}{|l|}{ Medical history, n (\%) } \\
\hline Diabetes mellitus & $19(6.8)$ & $31(8.8)$ & 0.354 \\
\hline Coronary artery disease & $21(7.5)$ & $15(4.2)$ & 0.080 \\
\hline History of stroke & $50(17.8)$ & $62(17.5)$ & 0.927 \\
\hline \multicolumn{4}{|l|}{ Lifestyle factors, n (\%) } \\
\hline Smoking & $62(22.1)$ & $88(24.9)$ & 0.41 \\
\hline Alcohol use & $100(35.6)$ & $120(33.9)$ & 0.657 \\
\hline \multicolumn{4}{|l|}{ Clinical features } \\
\hline Home SBP, $\mathrm{mmHg}$, mean $\pm \mathrm{SD}$ & $166 \pm 29$ & $160 \pm 29$ & 0.025 \\
\hline Home DBP, mmHg, median (IQR) & $92(80-106)$ & $90(80-100)$ & 0.008 \\
\hline $\mathrm{SBP}$ on admission, $\mathrm{mmHg}$, mean $\pm \mathrm{SD}$ & $|72 \pm 3|$ & $167 \pm 29$ & 0.019 \\
\hline DBP on admission, $\mathrm{mmHg}$, median (IQR) & $97(85-110)$ & $94(83-101)$ & 0.002 \\
\hline Neutrophil count, $10^{9} / \mathrm{L}$, mean $\pm S D$ & $9.3 \pm 4.2$ & $9.3 \pm 4.5$ & 0.979 \\
\hline Lymphocyte count, $10^{9} / \mathrm{L}$, mean $\pm S D$ & $1.2 \pm 0.6$ & $I . I \pm 0.6$ & 0.352 \\
\hline C-reactive protein, $\mathrm{mg} / \mathrm{L}$, mean $\pm \mathrm{SD}$ & $55.6 \pm 74.1$ & $62.3 \pm 66.2$ & 0.522 \\
\hline Procalcitonin, ng/mL, median (IQR) & $0.1(0.1-0.4)$ & $0.1(0.1-0.6)$ & 0.026 \\
\hline Interleukin-6, ng/L, mean $\pm S D$ & $41.7 \pm 52.1$ & $51.5 \pm 88.1$ & 0.485 \\
\hline Blood glucose, mmol/L, median (IQR) & $7.2(6.1-8.4)$ & $7.2(6.0-9.0)$ & 0.302 \\
\hline \multicolumn{4}{|l|}{ GCS score, n (\%) } \\
\hline $3-8$ & $55(19.6)$ & $|2|(34.2)$ & 0.000 \\
\hline $9-12$ & $74(26.3)$ & $79(22.3)$ & \\
\hline $13-15$ & $152(54.1)$ & $154(43.5)$ & \\
\hline \multicolumn{4}{|l|}{ Radiological data } \\
\hline Left, n (\%) & $132(47.0)$ & $172(48.6)$ & 0.686 \\
\hline \multicolumn{4}{|l|}{ Location, n (\%) } \\
\hline Supratentorial & $250(89.0)$ & $300(84.7)$ & 0.121 \\
\hline Infratentorial & $31(11.0)$ & $54(15.3)$ & \\
\hline ICH volume, $\mathrm{mL}$, median (IQR) & $25(15-40)$ & $25(15-45)$ & 0.289 \\
\hline Extension to ventricles, $\mathrm{n}(\%)$ & $89(31.7)$ & $142(40.1)$ & 0.028 \\
\hline Hematoma expansion, n (\%) & $45(16.0)$ & $49(13.8)$ & 0.444 \\
\hline
\end{tabular}

Abbreviations: $\mathrm{ICH}$, intracerebral hemorrhage; ACEls, angiotensin-converting enzyme inhibitors; ARBs, angiotensin II receptor blockers; SD, standard deviation; SBP, systolic blood pressure; DBP, diastolic blood pressure; GCS, Glasgow Coma Scale.

ACEIs/ARBs group and non-ACEIs/ARBs group $(\mathrm{p}=0.533)$.

Additionally, the relationship between perihematomal edema and hematoma volume was further investigated. The results presented that the perihematomal edema reached to the peak at 3 days $(24$ hours $[16.0 \pm$ $10.0 \mathrm{~mL}] ; 3$ days $[26.1 \pm 17.6 \mathrm{~mL}] ; 7$ days $[23.4 \pm$ $16.0 \mathrm{~mL}$ ]; $\mathrm{p}=0.000$ [24 hours versus 3 days]; $\mathrm{p}=0.116$ [3 days versus 7 days]). Then, Pearson correlation coefficient was used to determine the relationship between baseline hematoma and perihematomal edema. The results demonstrated that it exhibited a positive correlation at 24 hours $(\mathrm{r}=0.639, \mathrm{P}=0.000)$, perihematomal edema at 3 days $(\mathrm{r}=0.609, \mathrm{P}=0.000)$, and perihematomal edema at 7 days $(\mathrm{r}=0.671, \mathrm{P}=0.000)$.

\section{Discussion}

ICH is associated with higher mortality and disability than other types of strokes. ${ }^{4}$ Currently, the efficacy of treatments for ICH is still controversial. ${ }^{4}$ Increasing evidence have suggested that inflammation plays a key role in ICHinduced secondary brain injury. ${ }^{2,21}$ Hemoglobin, heme, 
Table 2 Anti-Hypertension Drugs of ICH Patients

\begin{tabular}{|l|l|l|l|l|}
\hline Variables & Total $(\mathbf{n = 6 3 5 )}$ & ACEIs/ARBs (n=28I) & Non-ACEIs/ARBs (n=354) & p value \\
\hline ACEls, n (\%) & $215(35.5)$ & $215(76.5)$ & $0(0.0)$ & 0.000 \\
ARB, n (\%) & $83(13.7)$ & $83(29.5)$ & $0(0.0)$ & 0.000 \\
CCB, n (\%) & $537(88.8)$ & $226(80.4)$ & $311(87.9)$ & 0.010 \\
$\alpha$-blocker, n (\%) & $27(4.5)$ & $0(0.0)$ & $27(7.6)$ & 0.000 \\
$\beta$-blocker, n (\%) & $41(6.8)$ & $21(7.5)$ & $20(5.6)$ & 0.353 \\
Diuretics, n (\%) & $47(7.8)$ & $45(16.0)$ & $2(0.6)$ & 0.000 \\
\hline
\end{tabular}

Abbreviations: ICH, intracerebral hemorrhage; ACEls, angiotensin-converting enzyme inhibitors; ARBs, angiotensin II receptor blockers; CCB, calcium channel blocker.

iron and thrombin released from the hematoma trigger inflammation via activation of microglia, and subsequently facilitate the infiltration of various circulating immune cells, especially macrophages and T cells. ${ }^{29}$ The activation of M1 microglia upregulates inflammatory cytokines, such as interleukin-1 $\beta$ (IL-1 $\beta$ ), tumor necrosis factor- $\alpha$ (TNF$\alpha$ ), and other inflammatory products via coordinating the transcription factor nuclear factor- $\mathrm{BB}(\mathrm{NF}-\mathrm{\kappa B}){ }^{2,21,30} \mathrm{The}$ upregulating of inflammatory cytokines lead to potentiating cellular damage, and increasing of permeability of blood brain barrier (BBB), which contributes to exaggeration of edema and further secondary ischemia by cell

Table 3 Clinical Courses and Outcomes of $\mathrm{ICH}$ Patients

\begin{tabular}{|l|l|l|l|}
\hline Variables & $\begin{array}{l}\text { ACEIs/ARBs } \\
\text { (n=28I) }\end{array}$ & $\begin{array}{l}\text { Non-ACEIs } \\
\text { IARBs (n=354) }\end{array}$ & P value \\
\hline $\begin{array}{l}\text { Treatment-related data, } n \text { (\%) } \\
\text { Surgery }\end{array}$ & $119(42.3)$ & $170(48.0)$ & 0.154 \\
Antiplatelet therapy & $22(7.8)$ & $18(5.1)$ & 0.157 \\
Anticoagulant therapy & $6(2.1)$ & $4(1.1)$ & 0.49 \\
Statins & $53(18.9)$ & $35(9.9)$ & 0.001 \\
Sulfonylureas & $12(4.3)$ & $17(4.8)$ & 0.75 \\
\hline Complications, n (\%) & & & \\
Hydrocephalus & $17(6.0)$ & $44(12.4)$ & 0.007 \\
Pneumonia & $164(58.4)$ & $236(66.7)$ & 0.031 \\
Mechanical ventilation & $52(18.5)$ & $84(23.7)$ & 0.111 \\
Gastrointestinal bleeding & $20(7.1)$ & $28(7.9)$ & 0.708 \\
Seizures & $7(2.5)$ & $10(2.8)$ & 0.796 \\
\hline Day, mean \pm SD & & & \\
Stay in NICU & $7.7 \pm 7.2$ & $7.9 \pm 7.8$ & 0.697 \\
Stay in hospital & $24.3 \pm 15.9$ & $20.7 \pm 16.9$ & 0.006 \\
\hline Outcomes, n (\%) & & & \\
Favorable outcome & $113(40.2)$ & $120(33.9)$ & 0.101 \\
Unfavorable outcome & $168(59.8)$ & $234(66.1)$ & \\
Death & $14(5.0)$ & $42(11.9)$ & 0.002 \\
Alive & $267(95.0)$ & $312(88.1)$ & \\
\hline
\end{tabular}

Abbreviations: $\mathrm{ICH}$, intracerebral hemorrhage; ACEls, angiotensin-converting enzyme inhibitors; ARBs, angiotensin II receptor blockers; NICU, neurological intensive care unit. death. ${ }^{13,31}$ The process of brain edema and secondary ischemia further exert inflammatory response to the surrounding brain tissue. ${ }^{2}$

The renin-angiotensin-aldosterone system (RAAS), which exists in the CNS, can influence the outcome of stroke. ${ }^{14,15}$ Angiotensin-converting enzyme inhibitor (ACEIs) and angiotensin II receptor blocker (ARBs) are two critical inhibitors of the RAAS and usually used as the first-line anti-hypertensive drugs. ${ }^{18}$ Meanwhile, previous studies have proven that ACEIs/ARBs can inhibit atherosclerosis processes and further reduce the risk of stroke recurrence. ${ }^{17,19,20,32,33}$ Moreover, previous studies have also revealed that ACEIs/ARBs may protect neural tissue, prevent secondary neuronal death after ICH including anti-oxidant, anti-apoptotic effects, and inhibit fibrinoid necrosis by a reduction of the generation of Ang II through the activation of the ACE2/Ang-(1-7)/Mas pathway. ${ }^{20,22-24}$ However, these results are not thoroughly attested by the clinical data. ${ }^{25}$

In the present study, our results illustrated that the usage of ACEIs/ARBs was associated with lower mortality in ICH sufferers with hypertension, compared with non-usage of ACEIs/ARBs (5.0\% [14 of 281] vs $11.9 \%$ [42 of 354], $\mathrm{p}=$ 0.002), which is in consistent with that the use of ACEIs/ ARBs are associated with lower risk of all-cause mortality compared with non-ACEI/ARB users in patients with COVID-19 and hypertension. ${ }^{34-37}$ Meanwhile, our results also demonstrated that the use of ACEIs/ARBs markedly lower the prevalence of ICH-associated pneumonia but without improvement in independent ability in ICH patients ( $40.2 \%$ vs $33.9 \%, p=0.101)$, implying that some other significant co-morbidities (eg, diabetes, previous stroke, and ischemic heart disease), the severity on admission, the white matter bundle injury, which needs long time to regenerate, might contribute to the equal outcome between two groups. ${ }^{25,38}$ These complicated pathophysiological effectors reduce the beneficial effect induced by ACEIs/ARBs, in some degree. 


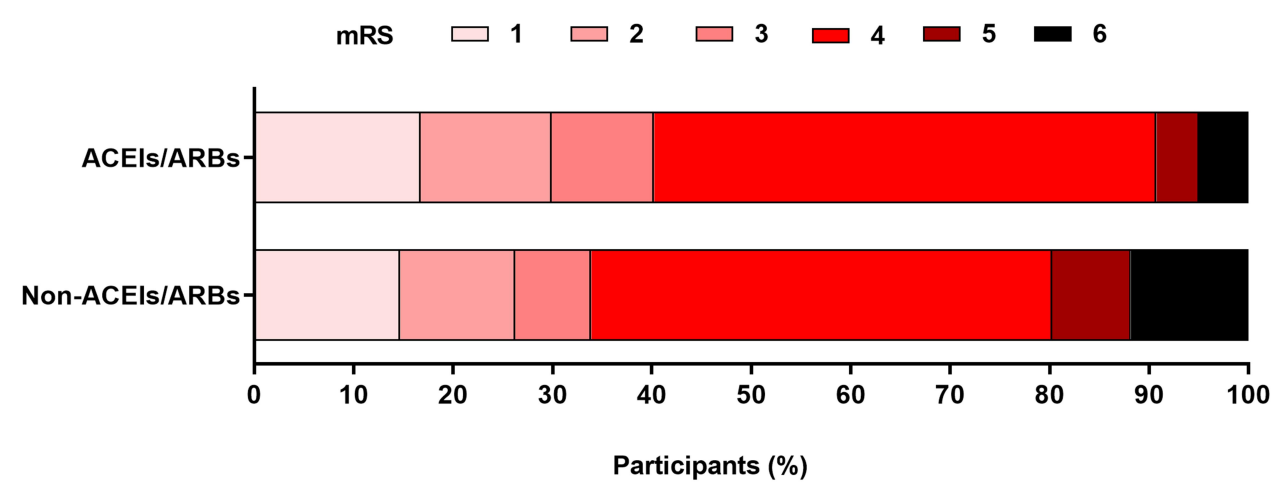

Figure 2 Modified Rankin Scale (mRS) of ICH patients at 3 months. Proportional odds model $p=0.007$.

Abbreviations: $\mathrm{ICH}$, intracerebral hemorrhage; ACEls, angiotensin-converting enzyme inhibitors; ARBs, angiotensin II receptor blockers.

The use of ACEIs/ARBs reduces perihematomal edema volume over 7 days after the occurrence of ICH with hypertension. Perihematomal edema, which ubiquitously occurs in ICH patients, is associated with mass

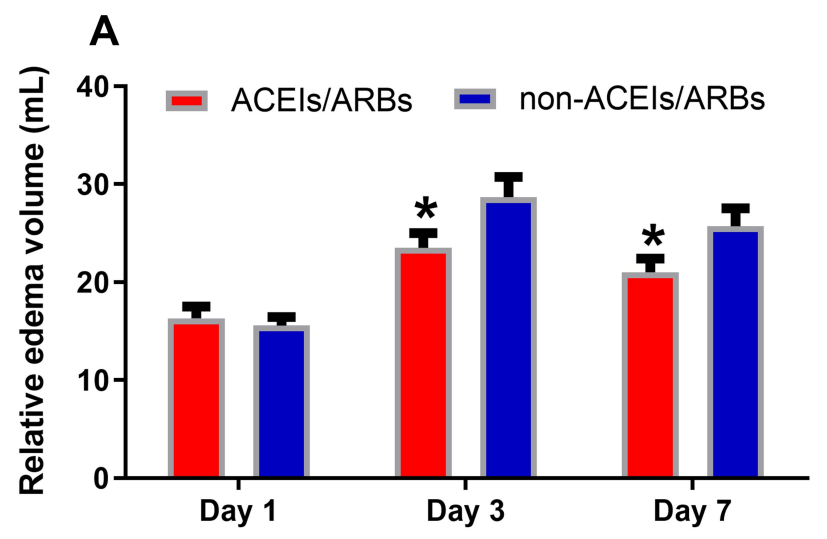

B

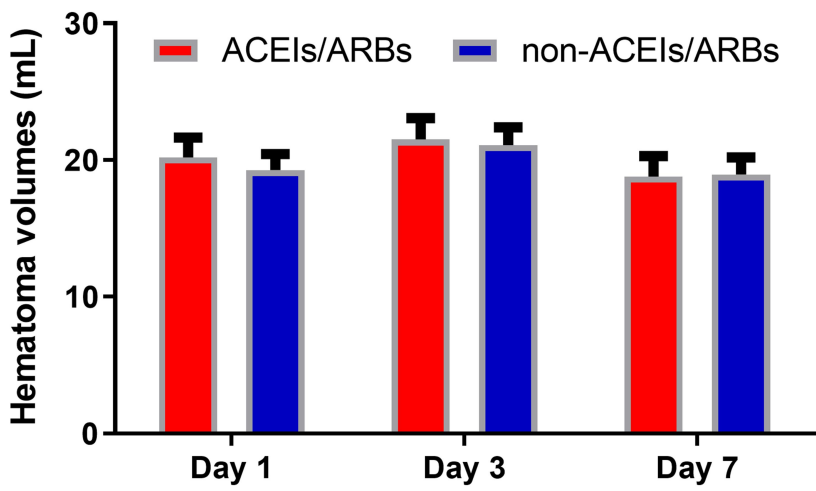

Figure 3 The lower perihematomal edema volume at day 3 and day 7 in $\mathrm{ICH}$ and hypertension patients with the usage of ACEls/ARBs. (A) The perihematomal edema volumes at baseline, day 3 and day 7 in ICH patients with or without the usage of ACEls/ ARBs. (B) The hematoma volumes at baseline, day 3 and day 7 in $\mathrm{ICH}$ and hypertension patients with or without the usage of ACEls/ARBs. Data were presented as Mean \pm SEM, $n=93$ for each group. $* \mathrm{P}<0.05$ vs non-ACEls/ARBs group.

Abbreviations: $\mathrm{ICH}$, intracerebral hemorrhage; ACEls, angiotensin-converting enzyme inhibitors; ARBs, angiotensin II receptor blockers. effect and is a predictor of poor outcome. ${ }^{3,39-41}$ The mechanisms of brain edema formation after ICH are complex, and several potential mechanisms contribute to the formation and progression of brain edema after $\mathrm{ICH}^{3}{ }^{3}$ The brain edema formation is rapid and follows three stages after ICH. ${ }^{3,10,42}$ In the first stage (a few hours after ICH), retraction of the clot contributes to vasogenic edema formation. In the second stage ( 24 to 48 hours after ICH), the activation of the coagulation cascade promotes edema formation and further disruption of the blood-brain barrier by the inflammatory cascade and overexpression of matrix metalloproteinase. In the third stage (days to weeks after ICH), erythrocyte lysis and hemoglobin/hemoglobin degradation products initiate a potent inflammatory reaction by the iron-catalyzed production of reactive oxygen species. Previous studies have represented that ACEIs/ ARBs could reduce the inflammatory cascade of reactive oxygen species, then relieve brain edema and improve neurological function. ${ }^{15,20,32,33,43}$ The reason why patients with supratentorial ICH, without intraventricular hemorrhage (IVH) and surgical treatments were screened and analyzed was due to avoiding technical flaws regarding accurate edema volume measurements, and exhibiting excellent repeat scans for perihematomal edema examination on day 3 to 4 and 7 to 8 of hospitalization, which is in line with previous report. ${ }^{27}$ Here, our results represented a positive correlation between hematoma volume and the perihematomal edema, which is supported by previous studies. $^{44,45}$

In addition, our results indicated that the occurrence of ICH-associated pneumonia was reduced with the use of ACEIs/ARBs $(p=0.031)$. The underlying mechanisms may be that the treatment of ACEIs/ARBs was associated with a reduction in myeloperoxidase activity and decreased 
cytokine and high-mobility group box 1 levels by an inhibition of NF- $\kappa \mathrm{B}$ activity. ${ }^{46,47}$ This neuroprotective effect needs to be elucidated through further animal experiments in our future research.

Some limitations still exist in the present study. First, due to the retrospective nature of this study, some data were not available in $\mathrm{ICH}$ patients. For instance, the laboratory data about inflammatory factors and the expression of ACE2 were failed to test. The dosage of antihypertensive drugs for patients was not recorded accurately. Second, many patients were excluded because of unavailable information of anti-hypertensive treatments, thereafter the selection bias might exist. Third, a multicentre, open, randomised trial needs to be carried out to attest the effectiveness of ACEIs/ARBs in ICH patients with hypertension. In addition, the underlying mechanisms that ACEIs/ARBs reduce the inflammatory response and $\mathrm{ICH}-$ related pneumonia post-ICH need to be explored using animal model studies.

\section{Conclusions}

Though the usage of ACEIs/ARBs cannot reduce the proportion of unfavorable outcome, it helps decrease mortality, perihematomal edema volume, and prevalence of $\mathrm{ICH}-$ associated pneumonia in ICH patients with hypertension, which enlarges the therapeutic application of ACEIs/ARBs, except for hypertension.

\section{Ethics and Consent Statements}

This study adheres to the principles of the Declaration of Helsinki. The protocol was approved by the Ethics Committee of the Southwest Hospital of Third Military Medical University, China (Ethical Approval no. KY2020114). Because it is a retrospective study that contained no identifiable data, informed consent was waived. Patients' privacy and personal identity information were well protected.

\section{Acknowledgments}

We thank the participants included in our trial for their involvement and enthusiasm.

\section{Funding}

This work was supported by grants from National Key R\&D Program of China (No. 2017YFC0111900) and Program for Innovation Research Group of Universities in Chongqing (No. CXQT19012).

\section{Disclosure}

The authors report no conflicts of interest in this work.

\section{References}

1. Wu S, Wu B, Liu M, et al. Stroke in China: advances and challenges in epidemiology, prevention, and management. Lancet Neurol. 2019;18(4):394-405. doi:10.1016/S1474-4422(18)30500-3

2. Keep RF, Hua Y, Xi G. Intracerebral haemorrhage: mechanisms of injury and therapeutic targets. Lancet Neurol. 2012;11(8):720-731. doi:10.1016/S1474-4422(12)70104-7

3. Balami JS, Buchan AM. Complications of intracerebral haemorrhage. Lancet Neurol. 2012;11(1):101-118. doi:10.1016/S1474-4422(11) 70264-2

4. van Asch CJ, Luitse MJ, Rinkel GJ, van der Tweel I, Algra A, Klijn CJ. Incidence, case fatality, and functional outcome of intracerebral haemorrhage over time, according to age, sex, and ethnic origin: a systematic review and meta-analysis. Lancet Neurol. 2010;9(2):167-176. doi:10.1016/S1474-4422(09)70340-0

5. Mendelow AD, Gregson BA, Fernandes HM, et al. Early surgery versus initial conservative treatment in patients with spontaneous supratentorial intracerebral haematomas in the international surgical trial in intracerebral haemorrhage (STICH): a randomised trial. Lancet. 2005;365(9457):387-397. doi:10.1016/S0140-6736(05) 70233-6

6. Mendelow AD, Gregson BA, Rowan EN, Murray GD, Gholkar A, Mitchell PM. Early surgery versus initial conservative treatment in patients with spontaneous supratentorial lobar intracerebral haematomas (STICH II): a randomised trial. Lancet. 2013;382 (9890):397-408. doi:10.1016/S0140-6736(13)60986-1

7. Hanley DF, Thompson RE, Rosenblum M, et al. Efficacy and safety of minimally invasive surgery with thrombolysis in intracerebral haemorrhage evacuation (MISTIE III): a randomised, controlled, open-label, blinded endpoint phase 3 trial. Lancet. 2019;393 (10175):1021-1032. doi:10.1016/S0140-6736(19)30195-3

8. Anderson CS, Heeley E, Huang Y, et al. Rapid blood-pressure lowering in patients with acute intracerebral hemorrhage. $N$ Engl $J$ Med. 2013;368(25):2355-2365. doi:10.1056/NEJMoa1214609

9. Wilkinson DA, Pandey AS, Thompson BG, Keep RF, Hua Y, Xi G. Injury mechanisms in acute intracerebral hemorrhage. Neuropharmacology. 2018;134(Pt $\quad$ B):240-248. doi:10.1016/j. neuropharm.2017.09.033

10. Thiex R, Tsirka SE. Brain edema after intracerebral hemorrhage: mechanisms, treatment options, management strategies, and operative indications. Neurosurg Focus. 2007;22(5):E6. doi:10.3171/ foc.2007.22.5.7

11. Xi G, Keep RF, Hoff JT. Mechanisms of brain injury after intracerebral haemorrhage. Lancet Neurol. 2006;5(1):53-63. doi:10.1016/ S1474-4422(05)70283-0

12. Babu R, Bagley JH, Di C, Friedman AH, Adamson C. Thrombin and hemin as central factors in the mechanisms of intracerebral hemorrhage-induced secondary brain injury and as potential targets for intervention. Neurosurg Focus. 2012;32(4):E8. doi:10.3171/ 2012.1.FOCUS11366

13. Tschoe C, Bushnell CD, Duncan PW, Alexander-Miller MA, Wolfe SQ. Neuroinflammation after intracerebral hemorrhage and potential therapeutic targets. $J$ Stroke. 2020;22(1):29-46. doi: $10.5853 /$ jos.2019.02236

14. von Bohlen Und Halbach O. The renin-angiotensin system in the mammalian central nervous system. Curr Protein Pept Sci. 2005;6 (4):355-371. doi:10.2174/1389203054546361

15. Culman J, Blume A, Gohlke P, Unger T. The renin-angiotensin system in the brain: possible therapeutic implications for AT (1)-receptor blockers. J Hum Hypertens. 2002;16(Suppl 3):S64-70. doi:10.1038/sj.jhh. 1001442 
16. Izzo JL, Moser M. Clinical impact of renin-angiotensin system blockade: angiotensin-converting enzyme inhibitors vs angiotensin receptor antagonists. J Clin Hypertens (Greenwich). 2002;4(6Suppl 2):11-19,31. doi:10.1111/j.1524-6175.2002.01361.x

17. da Silveira KD, Coelho FM, Vieira AT, et al. Anti-inflammatory effects of the activation of the angiotensin-(1-7) receptor, MAS, in experimental models of arthritis. J Immunol. 2010;185 (9):5569-5576. doi:10.4049/jimmunol.1000314

18. Kovell LC, Ahmed HM, Misra S, et al. US hypertension management guidelines: a review of the recent past and recommendations for the future. J Am Heart Assoc. 2015;4(12). doi:10.1161/JAHA.115.002315

19. Chang Y, Wei W. Angiotensin II in inflammation, immunity and rheumatoid arthritis. Clin Exp Immunol. 2015;179(2):137-145. doi:10.1111/cei.12467

20. Zheng J, Li G, Chen S, et al. Activation of the ACE2/Ang-(1-7)/Mas pathway reduces oxygen-glucose deprivation-induced tissue swelling, ROS production, and cell death in mouse brain with angiotensin II overproduction. Neuroscience. 2014;273:39-51. doi:10.1016/j. neuroscience.2014.04.060

21. Zhou Y, Wang Y, Wang J, Anne Stetler R, Yang QW. Inflammation in intracerebral hemorrhage: from mechanisms to clinical translation. Prog Neurobiol. 2014;115:25-44.

22. Ravati A, Junker V, Kouklei M, Ahlemeyer B, Culmsee C, Krieglstein J. Enalapril and moexipril protect from free radical-induced neuronal damage in vitro and reduce ischemic brain injury in mice and rats. Eur $J$ Pharmacol. 1999;373(1):21-33. doi:10.1016/S0014-2999(99)00211-3

23. Lonn E, Yusuf S, Dzavik V, et al. Effects of ramipril and vitamin E on atherosclerosis: the study to evaluate carotid ultrasound changes in patients treated with ramipril and vitamin E (SECURE). Circulation. 2001;103(7):919-925. doi:10.1161/01.CIR.103.7.919

24. Richer C, Fornes P, Vacher E, Bruneval P, Giudicelli JF. Trandolapril's protective effects in stroke-prone spontaneously hypertensive rats persist long after treatment withdrawal. Am J Cardiol. 1994;73(10):26c-35c. doi:10.1016/0002-9149(94)90620-3

25. Eichel R, Khouri ST, Cohen JE, et al. Prior use of angiotensin-converting enzyme inhibitors does not affect outcome in patients with intracerebral hemorrhage. Neurol Res. 2010;32 (9):905-909. doi:10.1179/016164110X12656393664928

26. Xing Y, An Z, Zhang X, et al. Sex differences in the clinical features, risk factors, and outcomes of intracerebral hemorrhage: a large hospital-based stroke registry in China. Sci Rep. 2017;7(1):286. doi:10.1038/s41598-017-00383-6

27. Mehdiratta M, Kumar S, Hackney D, Schlaug G, Selim M. Association between serum ferritin level and perihematoma edema volume in patients with spontaneous intracerebral hemorrhage. Stroke. 2008;39(4):1165-1170. doi:10.1161/STROKEAHA.1 07.501213

28. Dowlatshahi D, Demchuk AM, Flaherty ML, Ali M, Lyden PL, Smith EE. Defining hematoma expansion in intracerebral hemorrhage: relationship with patient outcomes. Neurology. 2011;76 (14):1238-1244. doi:10.1212/WNL.0b013e3182143317

29. Wang J, Doré S. Inflammation after intracerebral hemorrhage. J Cereb Blood Flow Metab. 2007;27(5):894-908. doi:10.1038/sj.jcbfm.9600403

30. Aronowski J, Zhao X. Molecular pathophysiology of cerebral hemorrhage: secondary brain injury. Stroke. 2011;42(6):1781-1786. doi:10.1161/STROKEAHA.110.596718

31. Wang J. Preclinical and clinical research on inflammation after intracerebral hemorrhage. Prog Neurobiol. 2010;92(4):463-477. doi:10.1016/j.pneurobio.2010.08.001

32. Zhou Y, Zeng YP, Zhou Q, Guan JX, Lu ZN. The effect of captopril on the expression of MMP-9 and the prognosis of neurological function in herpes simplex encephalitis mice. Neurol Res. 2016;38 (8):733-739. doi:10.1080/01616412.2016.1202462
33. Blezer EL, Nicolay K, Koomans HA, Joles JA. Losartan versus enalapril on cerebral edema and proteinuria in stroke-prone hypertensive rats. Am J Hypertens. 2001;14(1):54-61. doi:10.1016/S08957061(00)01231-0

34. Fosbøl EL, Butt JH, Østergaard L, et al. Association of angiotensin-converting enzyme inhibitor or angiotensin receptor blocker use with COVID-19 diagnosis and mortality. JAMA. 2020;324(2):168-177. doi:10.1001/jama.2020.11301

35. Xu J, Huang C, Fan G, et al. Use of angiotensin-converting enzyme inhibitors and angiotensin II receptor blockers in context of COVID-19 outbreak: a retrospective analysis. Front Med. 2020:1-12. doi:10.1007/s11684-019-0733-5

36. Yang G, Tan Z, Zhou L, et al. Effects of angiotensin II receptor blockers and ACE (angiotensin-converting enzyme) inhibitors on virus infection, inflammatory status, and clinical outcomes in patients with COVID-19 and hypertension: a single-center retrospective study. Hypertension. 2020;76(1):51-58. doi:10.1161/HYPER TENSIONAHA.120.15143

37. Zhang P, Zhu L, Cai J, et al. Association of inpatient use of angiotensin-converting enzyme inhibitors and angiotensin II receptor blockers with mortality among patients with hypertension hospitalized with COVID-19. Circ Res. 2020;126(12):1671-1681. doi:10.1161/CIRCRESAHA.120.317134

38. Jiang YB, Wei KY, Zhang XY, Feng H, Hu R. White matter repair and treatment strategy after intracerebral hemorrhage. CNS Neurosci Ther. 2019;25(10):1113-1125. doi:10.1111/cns.13226

39. Zazulia AR, Diringer MN, Derdeyn CP, Powers WJ. Progression of mass effect after intracerebral hemorrhage. Stroke. 1999;30 (6):1167-1173. doi:10.1161/01.STR.30.6.1167

40. Gebel JM, Jauch EC, Brott TG, et al. Relative edema volume is a predictor of outcome in patients with hyperacute spontaneous intracerebral hemorrhage. Stroke. 2002;33(11):2636-2641. doi:10.1161/01.STR.0000035283.34109.EA

41. Yang J, Arima H, Wu G, et al. Prognostic significance of perihematomal edema in acute intracerebral hemorrhage: pooled analysis from the intensive blood pressure reduction in acute cerebral hemorrhage trial studies. Stroke. 2015;46(4):1009-1013. doi:10.1161/ STROKEAHA.114.007154

42. Zheng H, Chen C, Zhang J, Hu Z. Mechanism and therapy of brain edema after intracerebral hemorrhage. Cerebrovasc Dis. 2016;42(34):155-169. doi:10.1159/000445170

43. Panahpour H, Dehghani GA. Inhibition of central angiotensin-converting enzyme with enalapril protects the brain from ischemia/reperfusion injury in normotensive rat. Daru. 2010;18(1):35-40.

44. Arima H, Wang JG, Huang Y, et al. Significance of perihematomal edema in acute intracerebral hemorrhage: the INTERACT trial. Neurology. 2009;73(23):1963-1968. doi:10.1212/WNL.0b013e $3181 \mathrm{c} 55 \mathrm{ed} 3$

45. Murthy SB, Moradiya Y, Dawson J, Lees KR, Hanley DF, Ziai WC. Perihematomal edema and functional outcomes in intracerebral hemorrhage: influence of hematoma volume and location. Stroke. 2015;46(11):3088-3092. doi:10.1161/STROKEAHA.115.010054

46. Hagiwara S, Iwasaka H, Matumoto S, Hidaka S, Noguchi T. Effects of an angiotensin-converting enzyme inhibitor on the inflammatory response in in vivo and in vitro models. Crit Care Med. 2009;37 (2):626-633. doi:10.1097/CCM.0b013e3181958d91

47. Arai T, Sekizawa K, Ohrui T, et al. ACE inhibitors and protection against pneumonia in elderly patients with stroke. Neurology. 2005;64(3):573-574. doi:10.1212/01.WNL.0000150897.14961.0F 


\section{Publish your work in this journal}

Neuropsychiatric Disease and Treatment is an international, peerreviewed journal of clinical therapeutics and pharmacology focusing on concise rapid reporting of clinical or pre-clinical studies on a range of neuropsychiatric and neurological disorders. This journal is indexed on PubMed Central, the 'PsycINFO' database and CAS, and is the official journal of The International Neuropsychiatric Association (INA). The manuscript management system is completely online and includes a very quick and fair peer-review system, which is all easy to use. Visit http://www.dovepress.com/testimonials.php to read real quotes from published authors.

Submit your manuscript here: https://www.dovepress.com/neuropsychiatric-disease-and-treatment-journal 